\title{
Differences in labelled triolein turnover after oral administration between liver and adipose tissue of rats
}

\author{
Nobuko Iritani*, Tomoe Kimura, Hitomi Fukuda and Tomomi Sugimoto \\ Faculty of Human and Cultural Studies, Tezukayama Gakuin University, 4-Cho, Harumidai, Sakai, Osaka 590-0113, Japan \\ (Received 9 March 2004 - Revised 26 July 2004 - Accepted 7 September 2004)
}

\begin{abstract}
To investigate exogenous triacylglycerol turnover, the time courses for labelled triolein in the liver, plasma and epididymal adipose tissue (adipose tissue) after oral administration to rats fed a fat-free or $10 \%$ corn oil diet for $3 \mathrm{~d}$ after fasting overnight were examined for $10 \mathrm{~d}$. After the administration of labelled triolein to rats fed the fat-free diet, the incorporation $(\mathrm{dpm} / \mathrm{g})$ into total lipids of the liver and adipose tissue each reached the maximum in $8 \mathrm{~h}$ and was seven times higher in the adipose tissue than in the liver. The half-lives of total lipid radioactivities during the decreasing phases were $0 \cdot 39$ and $2 \cdot 58 \mathrm{~d}$, respectively, in the rapid and slow phases of the decay curve in the liver, and $4.78 \mathrm{~d}$ in only one phase of the adipose tissue. Radioactivity after administration of labelled triolein was mostly found in the oleic acid in the tissues. The half-life of oleic acid was $3.92 \mathrm{~d}$ in the adipose tissues. These half-lives were similar in both dietary groups. Thus, although dietary corn oil reduced the triolein incorporation to cellular lipids in comparison to the fat-free diet, it did not affect these half-lives. The labelled triacylglycerol-oleic acid stayed abundantly intact for a long time in the adipose tissue and was scarcely changed to other fatty acids, whereas it was slightly incorporated into total lipids and quickly metabolized in the liver. Non-essential fatty acids may be mostly endogenous in the liver but may be exogenous and endogenous in adipose tissue.
\end{abstract}

Labelled triolein: Half-life: Liver: Adipose tissue

Compared with fatty acid synthesis and metabolism in the liver, the regulation of triacylglycerol (TAG) synthesis and metabolism is not so clear, particularly in epididymal adipose tissue (adipose tissue). In early studies, it has been shown that, under conditions that promote rapid lipogenic rates, the liver may synthesize as much as $30-50 \%$ of the body's fatty acids in mice and rats (Borensztain \& Getz, 1972; Hems et al. 1975; Baker et al. 1978; Kannan et al. 1980). It is likely that most of these newly made fatty acids are subsequently transported to the extrahepatic tissues for storage and use. Borensztain \& Getz (1972) estimated that about $50 \%$ of the ${ }^{14} \mathrm{C}$-labelled TAG-fatty acids in adipose tissue had been synthesized by the liver after injection of labelled glucose and then transported to the adipose tissue. However, Baker et al. (1981) concluded that, after intravenous injection of $\left[\mathrm{U}_{-}{ }^{14} \mathrm{C}\right]$ glucose in rats, virtually all of the radioactivity found in the adipose tissue of the rats was actually synthesized by the adipose tissue itself. These studies reported only the results for a short time after the injection of labelled glucose.

We previously found that, when perilla oil was orally given to rats, linolenic acid, an exogenous PUFA used as a marker, was quickly (in $1 \mathrm{~h}$ ) incorporated into liver lipids, and lipogenic enzyme mRNA gene expression was quickly (in $2 \mathrm{~h}$ ) suppressed by dietary PUFA (Iritani et al. 1998). The linolenic acid continued to increase during the first $4 \mathrm{~h}$, then decreased and almost disappeared by $48 \mathrm{~h}$. Therefore, exogenous TAG-fatty acids apparently are quickly incorporated into the liver lipids and quickly disappear. Although plenty of them were quickly metabolized and expired as $\mathrm{CO}_{2}$, the residue remained for a longer time in the adipose tissue
(Gordis, 1965; Pedersen \& Marqversen, 1981). Gordis (1965) found that little exchange of TAG-fatty acids occurred in rat adipose tissue in storage even after 2 months, and most TAG molecules in adipose depots are stored intact until mobilized. Carmaniu \& Herrera (1980) reported that the highest proportion of radioactivity from $\left[1-{ }^{14} \mathrm{C}\right]$ palmitate appeared in the esterified fatty acid in adipose tissue.

In the present experiment, in order to investigate the global turnover of TAG in liver and particularly in adipose tissue, the time courses for lipid elimination after oral administration of radioactive triolein were examined. The half-lives of the radioactivities in total lipids and oleic acid were calculated from the time courses, and compared in the liver and adipose tissue. The effects of dietary fat on them were also investigated.

\section{Materials and methods}

Chemicals

$\left[9,10-{ }^{3} \mathrm{H}(\mathrm{N})\right]$ Triolein $(148-740 \mathrm{GBq} / \mathrm{mmol})$ was purchased from Moravek Biochemicals, Inc. (Brea, CA, USA). Reagents were obtained mostly from Wako Pure Chemical Industries (Osaka, Japan) and Sigma (St Louis, MO, USA).

\section{Animals}

Male Wistar rats (Japan SLC Co., Hamamatsu, Japan), 4.5 weeks old (75-80 g body weight), fed on a commercially available 
non-purified diet (No. MF, Oriental Shiryo Co., Osaka, Japan) were food-deprived overnight and then fed a fat-free diet or a $10 \%$ (by weight) maize oil diet. The composition of the fat-free diet was (g/kg): sucrose, 763; casein, 200; cellulose, 50; salt mixture (Reeves et al. 1993), 40; choline chloride, 1; vitamin mixture (Reeves et al. 1993), 1. Corn oil replaced sucrose for the corn oil diet. The major fatty acid compositions of corn oil used were (\% in total fatty acids); 16:0, 9.47; 18:0, 1.93; 18:1, 33.8 and 18:2, 52.9. Rats were individually housed in wire-bottomed cages in a temperature-controlled room $\left(24^{\circ} \mathrm{C}\right)$ under an automatic lighting schedule ( 08.00 to 20.00 hours). The animals were allowed to consume ad libitum the diet and water.

The experimental design was as follows. The rats were orally given $1.85 \mathrm{MBq}\left[9,10-{ }^{3} \mathrm{H}(\mathrm{N})\right]$ triolein in $5 \mathrm{ml} 20 \%(\mathrm{v} / \mathrm{v})$ ethanol per $\mathrm{kg}$ body weight by a stomach tube at 09.00 hours $3 \mathrm{~d}$ after feeding the fat-free or $10 \%$ corn oil diet, and then killed $1,2,4,8,16 \mathrm{~h}$ and $1,2,4,7,10 \mathrm{~d}$ after the labelled triolein administration. Care and treatment of experimental animals were in accordance with the Guide for the Care and Use of Laboratory Animals (National Research Council, 1985).

Aliquots of liver, plasma and adipose tissue of the rats were immediately frozen in liquid nitrogen, and stored at $-80^{\circ} \mathrm{C}$ to extract total lipids as described later. The total lipids were used for TLC, GLC and HPLC.

\section{Lipid extraction, fractionation and GLC analysis}

Total lipids of liver, plasma and adipose tissue were extracted according to the method of Folch et al. (1957) and separated by TLC on silica gel H (Merck, Darmstadt, Germany). The fractions of TAG were separated by TLC with a solvent of chloroformmethanol-water $(65: 25: 4$, by vol.). The silica gel zone corresponding to TAG was identified by comparison with authentic standard, which was visualized by exposure to iodine vapor. The silica gel zones were scraped and the lipids were extracted with chloroform-methanol $(1: 1, \mathrm{v} / \mathrm{v})$. The recovery of TAG from the zones was over $90 \%$. Each TAG amount was corrected by each recovery. After saponification of the lipids with $1.79 \mathrm{M}-$ $\mathrm{KOH}$ ethanol at $60^{\circ} \mathrm{C}$ for $1 \mathrm{~h}$, the aqueous phase was washed with petroleum ether and acidified. The fractions were extracted with petroleum ether. The fatty acids were methylated with $m$-trifluoromethylphenyltrimethylammonium hydroxide and applied on to a Shimadzu 9A gas chromatograph equipped with a hydrogen flame detector. A capillary column of CBP-M20-025 (Shimadzu,
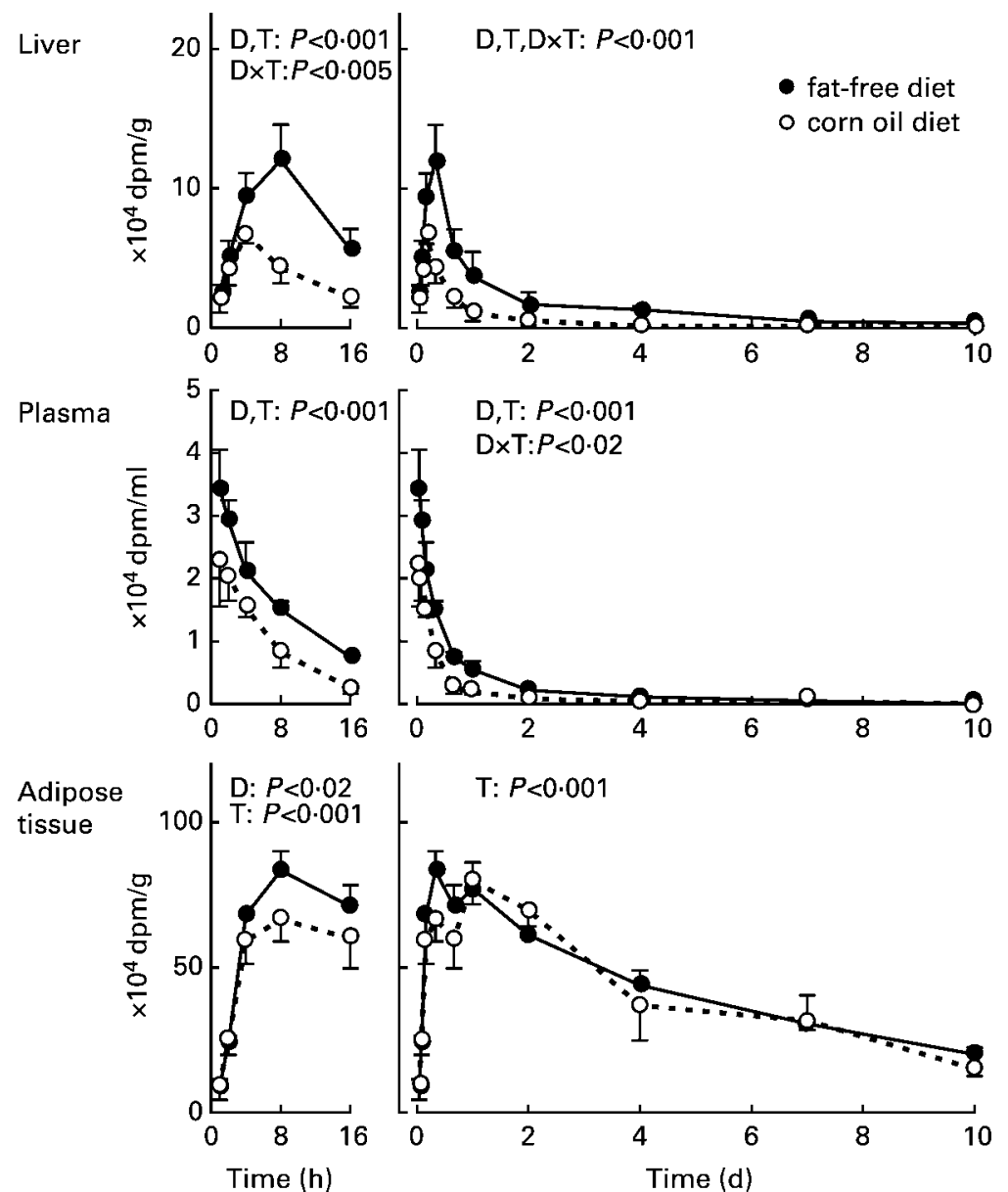

Fig. 1. Time courses for total lipid radioactivities in liver, plasma and epididymal adipose tissues after oral administration of labelled triolein to rats. Rats were food-deprived overnight and refed a fat-free or $10 \%$ corn oil diet for $3 \mathrm{~d}$. Then the rats were orally given $1.85 \mathrm{MBq}\left[9,10-{ }^{3} \mathrm{H}(\mathrm{N})\right]$ triolein. The rats were killed $1,2,4$, $8,16 \mathrm{~h}$ and $1,2,4,7,10 \mathrm{~d}$ after the administration. Total lipid radioactivities in tissues were measured. Total lipid radioactivities are shown as dpm/g or ml in the figures. Figures on the right show data for $1-16 \mathrm{~h}$ after the triolein administration, figures on the left show data for $1 \mathrm{~h}$ to $10 \mathrm{~d}$. Values are mean \pm SD $(n 4)$. Statistical analysis of two-way ANOVA for D (diet) and T (time) is shown in each panel. 
Kyoto, Japan), poly(ethylene glycol) coated in a tube $0.25 \mathrm{~mm} \times 25 \mathrm{~m}$ was programmed to increase from $60^{\circ} \mathrm{C}$ to $230^{\circ} \mathrm{C}$ at $6^{\circ} \mathrm{C} / \mathrm{min}$ and finally to maintain at $230^{\circ} \mathrm{C}$ for $20 \mathrm{~min}$. The carrier gas was $\mathrm{N}$.

\section{HPLC analysis}

Major endogenous fatty acids were separated and collected by HPLC. The quantities of fatty acids were measured using GC, the radioactivity was measured using a scintillation counter (LSC-5100, Aloka, Tokyo, Japan) and the specific activities (dpm/mg fatty acid) were calculated. HPLC analysis was performed with a Waters Associates (Milford, MA, USA) model 515 pump with the detection of a Waters 410 differential refractometer. A Simapack CLC-ODS (Shimazu, Kyoto, Japan) reversephase preparative column was used for separation. The mobile phase was acetonitoril-water $(85: 15, \mathrm{v} / \mathrm{v})$.

\section{Statistical analysis}

Two-way ANOVA was followed by an inspection of all difference between pairs of means using the least significant difference test (Snedecor \& Cochran, 1967). Differences were considered significant at $P<0.05$.

\section{Results and discussion}

Time courses for incorporation of labelled triolein into total lipids

After the oral administration of labelled triolein to rats fed the fat-free diet, the incorporation into total lipids of the liver and adipose tissue each reached the maximum in $8 \mathrm{~h}$ (Fig. 1). The incorporation per tissue $(\mathrm{dpm} / \mathrm{g})$ at the maximum was seven times higher in the adipose tissue than in the liver. The labelled triolein was incorporated only slightly into the total lipids in the liver and quickly decreased, whereas the triolein was greatly incorporated in the adipose tissue and remained at $25 \%$ of the maximum even after $10 \mathrm{~d}$. The exogenous total lipids stayed for much longer and more abundantly in the adipose tissue than in the liver. In the rats fed the corn oil diet, the incorporations at each maximum were about $50 \%$ and $80 \%$, respectively, of those in the liver and adipose tissue of the rats fed the fat-free diet. The incorporation of labelled triolein into plasma lipids quickly decreased without increasing.

Kalopissis et al. (1981) reported that, in fat-fed rats, the initial cellular uptake of $\left[1-{ }^{14} \mathrm{C}\right]$ oleate in vitro was decreased by $25 \%$, its esterification to TAG and phospholipids by $50 \%$, and its incorporation into VLDL TAG by $70 \%$. Thus, it is suggested that the cellular uptake of the labelled oleate, the esterification and the incorporation into VLDL may be decreased in the rats fed corn oil in the present experiment.

\section{Incorporation of labelled triolein into TAG}

The labelled triolein incorporation into TAG was compared with that into total lipids (shown in Fig. 1). The results are shown in Fig. 2. The incorporation into TAG in the liver was about parallel to that into total lipids: $77 \%$ (average) of that into total lipids 2$16 \mathrm{~h}$ after administration in the rats fed the fat-free diet, and $66 \%$ (average) of that in the rats fed the corn oil diet (Fig. 2). The incorporation into TAG in the adipose tissue was also parallel fat-free diet

corn oil diet
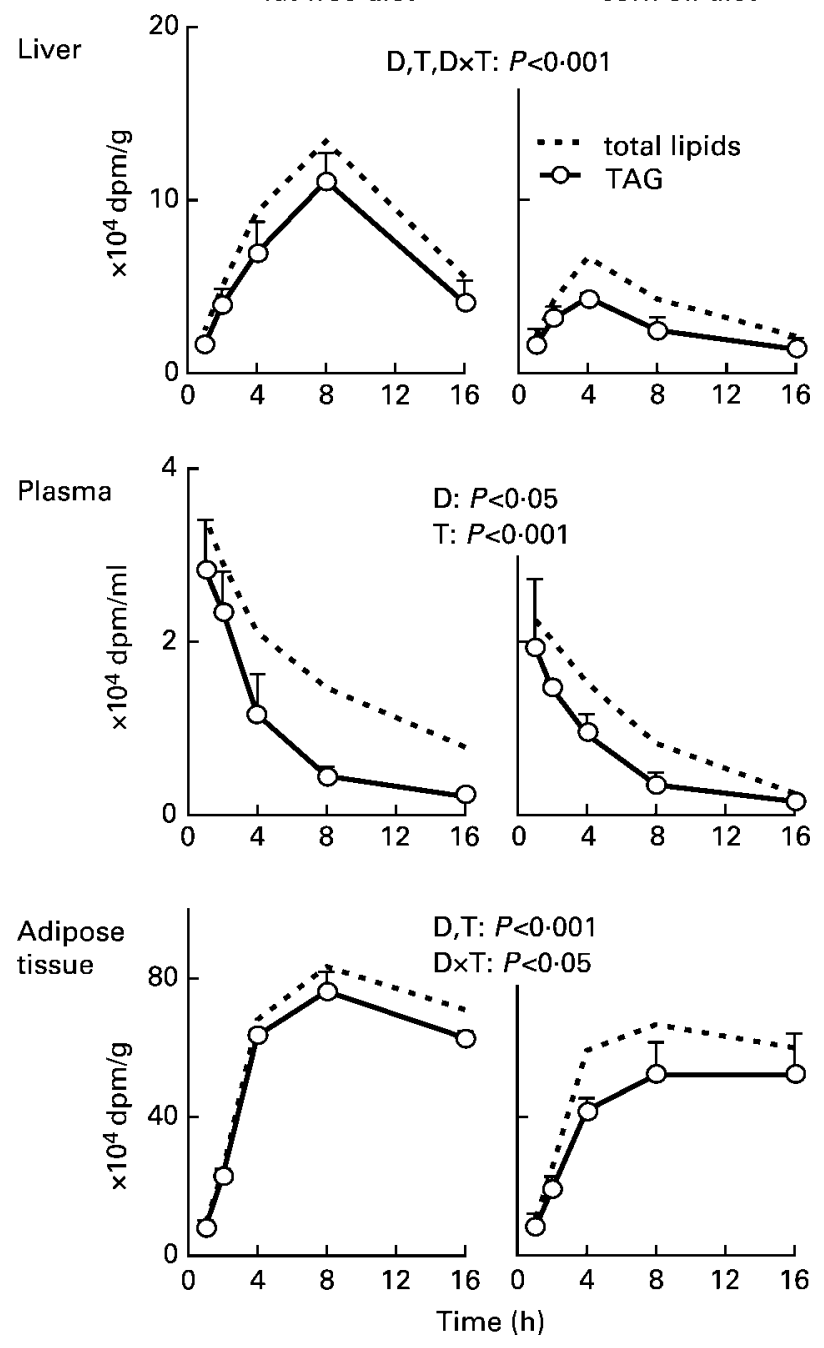

Fig. 2. Labelled triolein incorporation into TAG in liver, plasma and adipose tissue after oral administration to rats. Rats were orally given the labelled triolein as described in the legend of Fig. 1. The labelled triolein incorporation into TAG was shown in comparison with the incorporation into total lipids (taken from Fig. 1). Values are mean $\pm S D(n$ 4). Each figure on the left shows the results for rats fed the fat-free diet, and the figure on right, those for rats fed the corn oil diet. Two-way ANOVA for D (diet) and T (time) in triolein incorporation into TAG (solid line) are shown above the panels.

to that into total lipids: $91 \%$ (average) of that into total lipids in the rats fed the fat-free diet, and $78 \%$ (average) in those fed the corn oil diet. The incorporation of exogenous triolein into total lipids and TAG was significantly lower in the livers and adipose tissues of rats fed the corn oil diet than in those fed the fatfree diet. In rats fed the corn oil diet, it was found that dietary PUFA decreased the triolein incorporation into total lipids due to the reduction of the incorporation into TAG in the tissues. The incorporation of labelled triolein into plasma TAG quickly decreased without increasing similarly to the total lipids.

TAG were separated by TLC from total lipids, and the TAG radioactivities were corrected by the recovery. The triolein incorporation of total lipids could be more accurately measured without the TLC process than that of TAG. As the incorporation into TAG was about parallel to that of total lipids, the incorporations were shown by total lipid radioactivity. Changes in total lipids are considered to be correlated to those in TAG. 


\section{Half-lives}

After the oral administration of labelled triolein, semi-logarithmic plots of total lipid radioactivities against time during the decreasing phases in the rat liver, plasma and adipose tissue are shown in Fig. 3. The regression lines were calculated by computer analysis using the data in Fig. 1. The decay curves were about parallel between the rats fed the fat-free diet and those fed the corn oil diet. Triolein was rapidly metabolized at an early stage (the rapid phase) after administration and the residue was slowly metabolized (the slow phase). The half-lives in the livers were 0.39 and $0.33 \mathrm{~d}$, respectively, in the rapid phases of the rats fed the fat-free diet and corn oil diet, and 2.58 and $2.54 \mathrm{~d}$, respectively, in the slow phases of both dietary groups. The decay curves in plasma were also about parallel between the rats fed the fat-free diet and those fed the corn oil diet. The half-lives in the slow phases were similar in the liver and plasma, whereas those in the rapid phases were rather shorter in the plasma.

In the adipose tissue, the decay curves were similar in the two dietary groups. The half-lives were similar in only one phase, 4.78 and $4.10 \mathrm{~d}$, respectively, in the rats fed the fat-free diet and those fed the corn oil diet. The half-lives were similar in the liver and plasma, but much longer in the adipose tissue than in the liver and plasma.

The half-lives for the specific activities of oleic acid in adipose tissue, shown in Fig. 4, were calculated from Fig. 5. The half-lives for the specific activities of oleic acid in adipose tissue were close to those of the total lipids, and were 3.92 and $3.43 \mathrm{~d}$, respectively, in the rats fed the fat-free diet and the corn oil diet. The turnover rate of oleic acid was similar in both dietary groups.

Thus, the decay curves in liver, plasma and adipose tissue were about parallel between the rats fed the fat-free diet and those fed the corn oil diet. Although dietary corn oil reduced the triolein incorporation into lipids, it did not affect the half-lives. It is suggested that dietary PUFA did not affect the decay of TAG but suppressed the labelled triolein incorporation into the liver TAG (Fig. 2). The cellular uptake of the labelled oleate, the esterification and the incorporation into VLDL may be decreased in the rats fed corn oil in the present experiment (Kalopissis et al. 1981).

\section{HPLC analysis}

The labelled triolein incorporation into each fatty acid (major fatty acids except essential fatty acids) in the liver, plasma and adipose tissue of rats is shown as specific activities (dpm/mg fatty acid) in Fig. 5. After the oral administration of triolein, the time course for the specific activities of oleic acid was similar to that of total lipids in each tissue (shown in Fig. 1). Radioactivity after administration of labelled triolein was mostly found in the oleic acid fraction in the liver, plasma and adipose tissue. The specific activities of oleic acid were markedly higher than those of the other fatty acids, which were very slight in both the fat-free and corn oil diet groups. The oleic acid was scarcely metabolized to other fatty acids. The specific activities of oleic acid were significantly lower in rats fed the corn oil diet than in those fed the fat-free diet.

Gordis (1965) concluded that most TAG molecules in adipose depots are stored intact until mobilized. Moreover, Carmaniu \& Herrera (1980) reported that the highest proportion of radioactivity from $\left[1-{ }^{14} \mathrm{C}\right]$ palmitate appeared in the esterified fatty acid in adipose tissue. These reports support our present results. Thus, labelled triolein may be mostly stored as intact triolein.

It has been shown that the liver may synthesize abundantly the body's fatty acids in mice and rats (Borensztain \& Getz, 1972; Hems et al. 1975; Baker et al. 1978; Kannan et al. 1980). It is likely that most of these newly made fatty acids are subsequently transported to the extrahepatic tissues for storage and use. Borensztain \& Getz (1972) estimated that about $50 \%$ of the ${ }^{14} \mathrm{C}$ labelled TAG-fatty acids in adipose tissue had been synthesized by the liver after injection of labelled glucose and then transported to the adipose tissue. In the present experiment, the incorporation of labelled triolein into plasma lipids, in contrast to the increase in adipose tissue, quickly decreased similarly to that in the liver. The half-lives of labelled triolein during the decreasing phase were similar in the liver and the plasma. Thus, it is suggested that the labelled triolein may be partially transported from liver to adipose tissue via plasma but may be mostly metabolized in the liver.
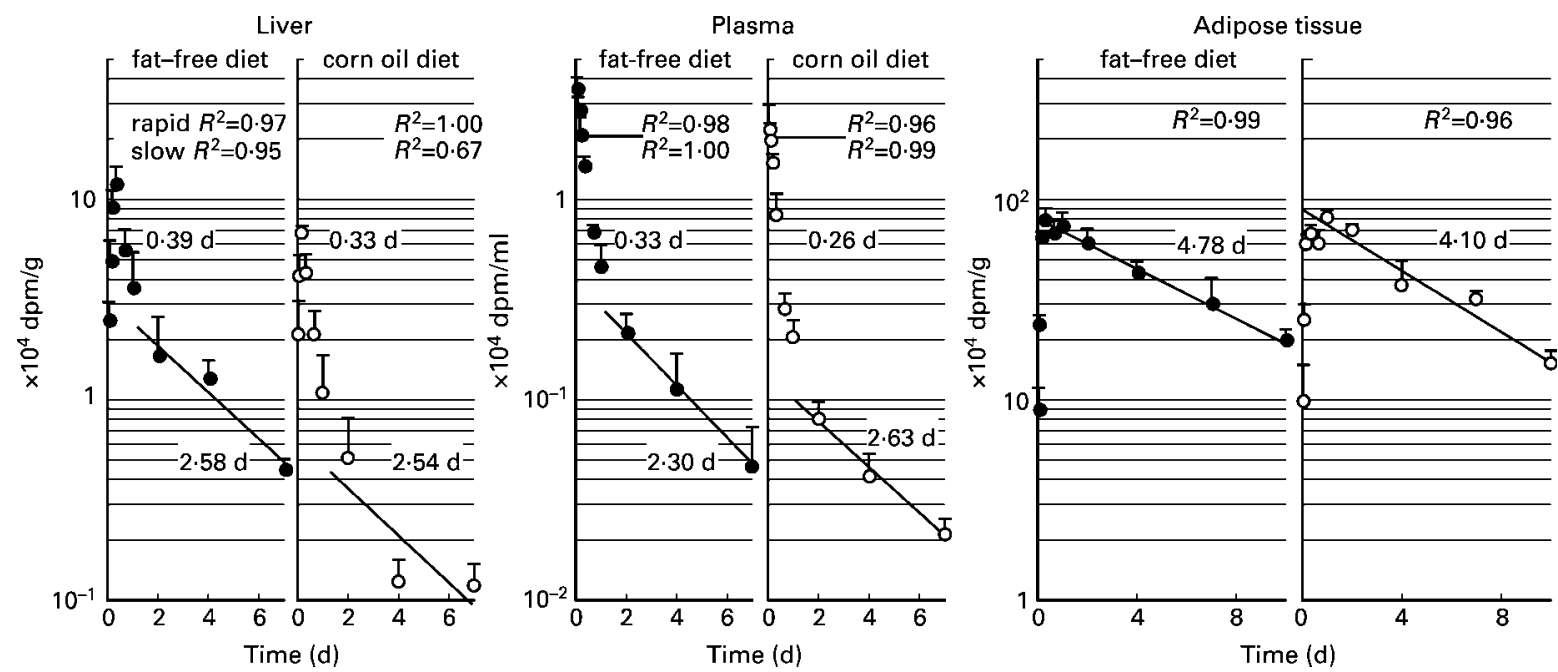

Fig. 3. Semi-logarithmic plots of total lipid radioactivities in liver, plasma and adipose tissue, and oleic acid specific activities in adipose tissue after oral administration of labelled triolein to rats. The total lipid radioactivities ( $\mathrm{dpm} / \mathrm{g}$ or $\mathrm{ml}$ ) in the liver, plasma and adipose tissue were plotted against time on semi-logarithmic graphs. The regression lines and half-lives were calculated by computer analysis. The half-lives are written on the graphs. The correlations of the regression lines are given: the upper and lower factors are shown for the rapid and slow phases, respectively. 


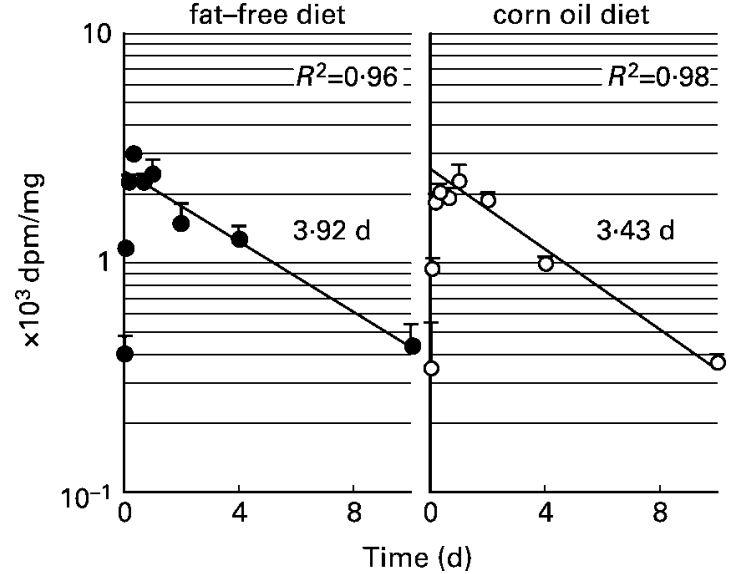

Fig. 4. Semi-logarithmic plots of oleic acid specific activities in adipose tissue after oral administration of labelled triolein to rats. The oleic acid specific activities (dpm/mg oleic acid) in adipose tissue (shown in Fig. 5) were also plotted against time on a semi-logarithmic graph. The regression lines and half-lives were calculated by computer analysis. The half-lives are written on the graphs. The correlations of the regression lines are given.

On the other hand, in the present experiment, the rats were fed the fat-free or corn oil diet for $3 \mathrm{~d}$ after fasting overnight. Because we previously found that the induction of lipogenic enzymes (acetyl-CoA carboxylase, fatty acid synthase and others) in liver (Iritani, 1993) and in adipose tissue (Iritani et al. 1996) reached a steady state $3 \mathrm{~d}$ after the refeeding. Lipogenic enzyme activities and TAG concentrations in the liver were lowered to minimum levels in rats given the $10 \%$ (by weight) corn oil diet for $3 \mathrm{~d}$ (Iritani et al. 2000). Dietary perilla oil (5\%) began to change the fatty acid compositions of liver $1 \mathrm{~h}$ after feeding, the exogenous fatty acids increased for the first $4 \mathrm{~h}$, then decreased and almost disappeared by $48 \mathrm{~h}$ (Iritani et al. 1998). Therefore, feeding the diet for $3 \mathrm{~d}$ was considered to be enough for fatty acid compositions to reach a steady state in the liver. Lambert et al. (1998) showed that different types of fat given in the diet for $21 \mathrm{~d}$ have different effects on the hepatic uptake and metabolism of lipids carried in chylomicron remnants of the corresponding fatty acid composition. The experimental methods are completely different from ours. However, adaptive changes, which occur in the rat liver on long-term feeding of different types of fat, may have effects on the uptake and metabolism of chylomicron remnants.

In summary, after the oral administration of labelled triolein to rats, the incorporation $(\mathrm{dpm} / \mathrm{g})$ into total lipids of the liver and adipose tissue reached the maximum in $8 \mathrm{~h}$ and was seven times higher in the adipose tissue than in the liver. The half-life of total lipids and oleic acid was much longer in the adipose tissue than in the liver. Radioactivity after administration of labelled triolein was mostly found in oleic acid in the liver, plasma and adipose tissue. The oleic acid was scarcely metabolized to other fatty acids. Exogenous triolein may be mostly stored intact until mobilized. Thus, exogenous oleic acid stayed abundantly intact for a long time in the adipose tissue, whereas it was only slightly incorporated into lipids and quickly metabolized in the liver. Non-essential fatty acids may be mostly endogenous in the liver but may be exogenous as well as endogenous in adipose tissue. Although the triolein incorporation into TAG was reduced by dietary corn oil in comparison with the fat-free diet, the half-lives of oleic acid were not affected.
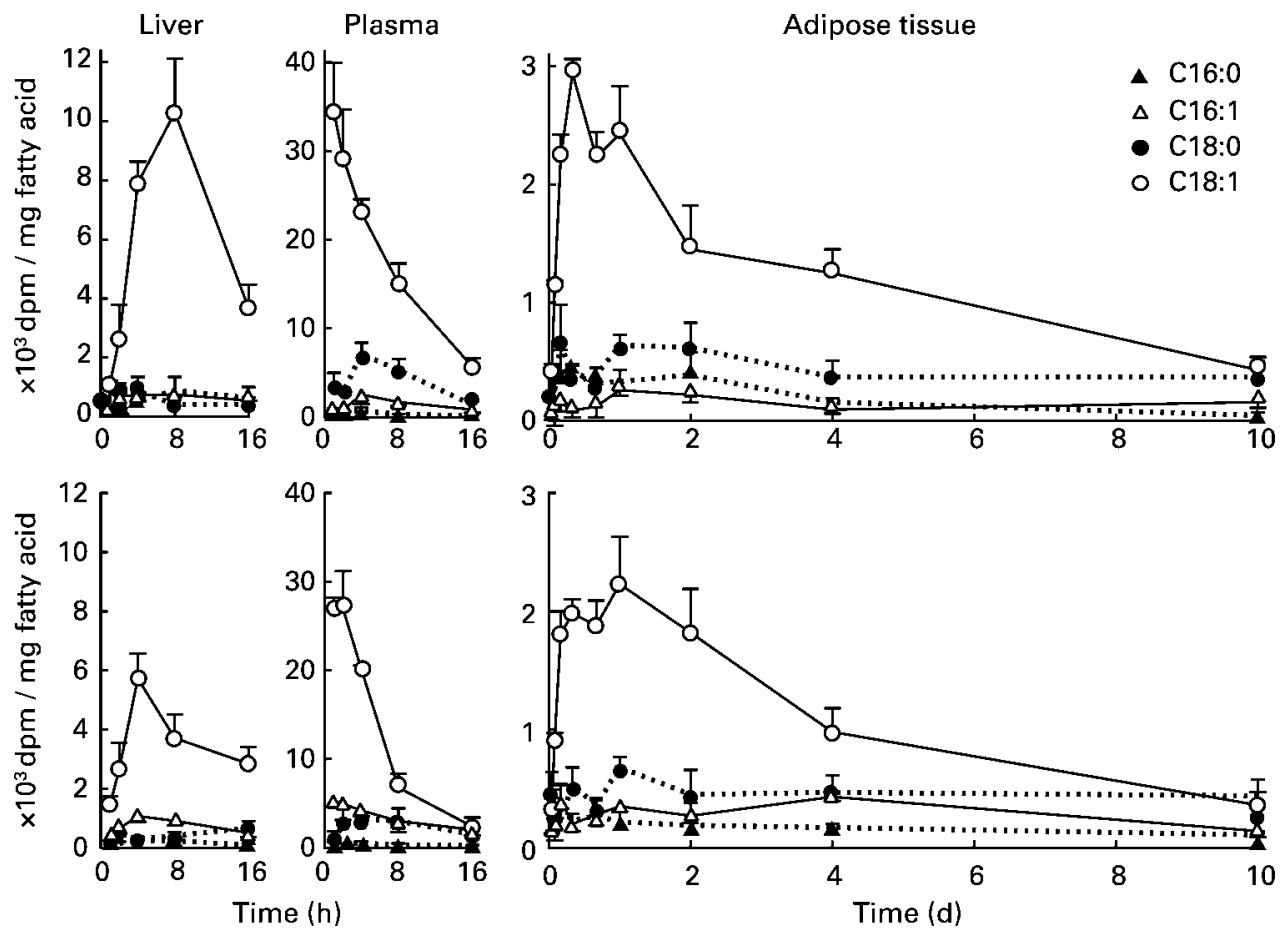

Fig. 5. Time courses for specific activities of each fatty acid in adipose tissue after oral administration of triolein to rats. Rats were orally given the labelled triolein as described in the legend of Fig. 1. Values are mean \pm SD ( $n$ 4). Two-way ANOVA for oleic acid from other fatty acids: $F($ other fatty acids), $T$ (time), $F \times T$, $P<0.001$ in liver, plasma and adipose tissues of rats fed the fat-free (upper) or corn oil (lower) diet. Two-way ANOVA for oleic acid between rats fed the fat-free (upper) and corn oil (lower) diet: T, D (diet), $T \times D, P<0.05$ in liver, plasma and adipose tissues. 


\section{Acknowledgements}

This work was supported by the Fund of Tezukayama Gakuin University and Japan Private School Promotion Funds.

\section{References}

Baker N, Learn DB \& Bruckdorfer KR (1978) Re-evaluation of lipogenesis from dietary glucose carbon in liver and carcass of mice. J Lipid Res 19, 879-893.

Baker N, Mead J Jr \& Kannan B (1981) Hepatic contribution to newly made fatty acids in adipose tissue in rats and inhibition of hepatic and extrahepatic lipogenesis from glucose by dietary corn oil. Lipids 16, 568-576.

Borensztain J \& Getz GS (1972) The contribution of lipogenesis in situ to the accumulation of fat by rat adipose tissue. Biochim Biophys Acta 280, 86-93.

Carmaniu S \& Herrera E (1980) Comparative utilization in vivo of [U- $\left.{ }^{14} \mathrm{C}\right]$ glycerol, $\left[2-{ }^{3} \mathrm{H}\right]$ glycerol, $\left[\mathrm{U}_{-}{ }^{14} \mathrm{C}\right]$ glucose and $\left[1-{ }^{14} \mathrm{C}\right]$ palmitate in the rat. Arch Int Physiol Biochim 88, 255-263.

Folch J, Lees M \& Sloane-Stanley GH (1957) A simple method for isolation and purification of total lipids from animal tissues. $J$ Biol Chem 226, 497-509.

Gordis E (1965) The long-term stability of triglyceride molecules in adipose tissue. J Clin Invest 44, 1978-1985.

Hems DA, Rath EA \& Verrinder TR (1975) Fatty acid synthesis in liver and adipose tissue of normal and genetically obese (ob/ob) mice during the 24-hour cycle. Biochem J 150, 167-173.

Iritani N (1993) A review: Nutritional and hormonal regulation of lipogenic enzyme gene expression in rat liver. Eu J Biochem 205, $433-442$.

Iritani N, Fukuda H \& Tada K (1996) Nutritional regulation of lipogenic enzyme gene expression in epididymal adipose tissue. $J$ Biochem (Tokyo) 120, 242-248.

Iritani N, Kimura T, Fukuda H \& Sugimoto T (2000) Effects of dietary fatty acid on tissue fatty acid compositions in rats. $J$ Jpn Soc Food Sci 53, 249-257.

Iritani N, Komiya M, Fukuda H \& Sugimoto T (1998) Lipogenic enzyme gene expression is quickly suppressed in rats by a small amount of exogenous polyunsaturated fatty acids. J Nutr 128, 967-972.

Kalopissis AD, Grioglio S, Malewiak MI, Rozen R \& Liepvre XL (1981) Very-low-density-lipoprotein secretion by isolated hepatocytes of fatfed rats. Biochem J 198, 373-377.

Kannan R, Elovson J, Learn DB \& Baker N (1980) Fatty acid synthesis in vivo and hepatic contribution to whole-body lipogenic rates in obese Zucker rats. Lipids 15, 993-998.

Lambert MS, Avella MA, Botham KM \& Mayes PA (1998) Comparison of short- and long-term effects of different dietary fats on the hepatic uptake and metabolism of chylomicron remnants in rats. $\mathrm{Br} J$ Nutr 79, 203-211.

National Research Council (1985) Guide for the Care and Use of Laboratory Animals. Publication no. 85-23 (rev.). Bethesda, MD: National Institute of Health

Pedersen NT \& Marqversen J (1981) Metabolism of ingested ${ }^{14} \mathrm{C}$-triolein. Estimation of radiation dose in tests of lipid assimilation using ${ }^{14} \mathrm{C}$ - and ${ }^{3} \mathrm{H}$-labeled fatty acids. Eur J Nucl Med 6, 327-329.

Reeves PG, Nielsen FH \& Fahey GC Jr (1993) Purified diets for laboratory rodents: final report of the American Institute of Nutrition ad hoc writing committee on the reformation of the AIN-76A rodent diet. J Nutr 123, 1939-1951.

Snedecor GW \& Cochran WG (1967) Statistical Methods, pp. 285-338. Ames: Iowa State University Press. 